\title{
COVID-19 and the history of antiseptic surgery: how to tackle these little beasts
}

This article was published on 3 Jun 2020 at www.hkmj.org.
Teresa Tan ${ }^{1}$ *, MB, ChB, FCSHK, CH Yee², MB, BS, FCSHK, CF Ng${ }^{2}$, MB, ChB, FCSHK, Jeremy YC Teoh², MB, BS, FCSHK

${ }^{1}$ Division of Plastic and Reconstructive Surgery, Department of Surgery, Prince of Wales Hospital, The Chinese University of Hong Kong, Hong Kong

${ }^{2}$ SH Ho Urology Centre, Department of Surgery, Prince of Wales Hospital, The Chinese University of Hong Kong, Hong Kong

*Corresponding author: teresa@surgery.cuhk.edu.hk

Hong Kong Med J 2020;26:258-9

https://doi.org/10.12809/hkmj208617

"Where are these little beasts? Show them to us, and we shall believe in them." These were the words John Hughes Bennett said to Joseph Lister, challenging his theory on aseptic techniques using carbolic acid. In 1867, Joseph Lister first published an account of his use of carbolic acid in a series of articles on preventing wound infections in compound fractures and abscesses. ${ }^{2,3}$ However, his theory of aseptic techniques was mocked and widely criticised in his early career; an article published in 1873 warned the medical profession against Lister's ideas of antiseptics. ${ }^{4}$

Despite the negative comments and responses from the medical field, Lister believed in his theory and persevered. ${ }^{5}$ After many more publications and meetings, his theory of antiseptic surgery was eventually adopted. He gained recognition for his works during his lifetime and was awarded the Cameron Prize for Therapeutics of the University of Edinburgh in 1890. Today, the name Joseph Lister rings a bell for both surgeons and physicians alike, and he is known as the father of modern surgery or the pioneer of antiseptic surgery. His name can also be found on a common household product: Listerine mouthwash is actually named after Joseph Lister! $^{6}$

However, not all scientists whose brilliant ideas got rejected survived to witness their theories being put into practice. Take for example Ignaz Semmelweis, a Hungarian obstetrician who first proposed the idea that hand washing saves lives. ${ }^{7}$ In the early 1800 s he noticed that the incidence of puerperal fever could be lowered by the use of disinfection. In 1847, his findings were published, showing that when doctors washed their hands before examining patients, the mortality rate for women in his obstetrics ward was greatly reduced. ${ }^{8}$ He also published a number of studies showing that hand washing could reduce mortality to below $1 \%$.

Despite various publications by Semmelweis, the medical community back then rejected his ideas and theories. ${ }^{9}$ Doctors did not know about the existence of germs, and Semmelweis could not offer any acceptable scientific evidence for his findings.
At that time, blood-stained hands and scrubs were the proud battle marks of a busy and successful surgeon, and many were offended by Semmelweis suggesting for them to wash their hands. He was heavily mocked by his peers. Nevertheless, the outspoken Semmelweis continued to try to convince the medical community to wash their hands, and subsequently suffered a nervous breakdown, and was sent to a Viennese asylum by his colleague where he was held in a straitjacket. Sadly, he died 14 days later, most likely from beatings from the guards that caused a gangrenous wound on his hand. What made this tragedy even more tragic was that after his death, the hospital that he worked at went back to its old habits without hand washing, discarding Semmelweis' "crazy ideas", and nobody cared that mortality rates increased by a factor of six.

Semmelweis never lived to celebrate the success of his theory. It was only decades later when germ theory was described by Louis Pasteur and Joseph Lister that it became accepted that antiseptic techniques could indeed save lives. Semmelweis is now recognised as a pioneer of antiseptic techniques, and in 2008, he was selected as the motif for the $€ 50$ Austrian commemorative coin, in a series that celebrated physicians of Austria.

These two prominent physicians share common traits: they both paid vigilant attention to details of their patients, possessed inquisitive minds, and were constantly questioning their own practices and striving for improvement of patient care and patient survival. Both conceived new concepts and ideas, advocated for them to be put in place after early clinical observations, and were initially rejected by the medical community. It was only decades later that their theories were put into practice and widely talked about.

Fast forward to 2020, the most talked about issue worldwide today is the coronavirus disease 2019 (COVID-19) pandemic which spread rapidly internationally and caught many unprepared. Many medical systems are overwhelmed and overburdened by this sudden disease, and different countries have adopted different practices to limit the spread. One 
hotly debated topic is whether to have the general public wear masks, including handmade or reusable masks. At the time of writing, there are no large-scale studies to prove nor disprove the theory that this "universal masking" can help contain and control COVID-19. The general populations in Hong Kong, China, and Taiwan and some other Asian territories started wearing masks in early 2020. In contrast, Western populations tend to follow official advice that advocates mask-wearing only for the sick and immunocompromised, and those working in close proximity.

Observing the total numbers of COVID-19 cases, the disease somewhat seems better controlled in countries/regions where mask-wearing is common, such as Hong Kong, China, and Taiwan. As numbers of confirmed cases of COVID-19 increased, some countries such as the United States shifted towards recommending mask-wearing in public areas. In mid-April, Singapore made it mandatory to wear a mask when stepping out of the house. ${ }^{10}$ Other viruscontrol methods are also important, not least hand washing, as well as social distancing, quarantines, school closures, and restrictions on travel and mass gatherings. ${ }^{11}$ It is difficult to identify whether one measure is more effective than another in supressing virus transmission, and most likely these measures add up synergistically.

As the saying goes, "Prevention is better than cure". To tackle the worldwide problem of COVID19 , it may be worth considering universal masking to control spreading of the disease. Despite the lack of strong evidence to prove the effectiveness of universal masking in preventing the spread of COVID-19, it is a simple practice, and there is evidence that maskwearing helps control spread of aerosols. ${ }^{12}$

History has shown that it is not easy to change one's practice overnight, as shown by the lives of Lister and Semmelweis. Yet, in today's world where COVID-19 caught us off guard, we need to be flexible and think of feasible and practical methods to control its spread. There is little doubt that universal masking may be inconvenient and uncomfortable for some, yet considering the human lives at stake, it is a small inconvenience to help control the epidemic.

So, will universal masking help control the spread of COVID-19? Only time will tell.

\section{Author contributions}

All authors contributed to the concept and design of the study, drafting of the manuscript, and critical revision of the manuscript for important intellectual content. All authors had full access to the data, contributed to the study, approved the final version for publication, and take responsibility for its accuracy and integrity.

\section{Conflicts of interest}

As an editor of the journal, JYC Teoh was not involved in the peer review process. Other authors have no conflicts of interest to disclose.

\section{Funding/support}

This commentary received no specific grant from any funding agency in the public, commercial, or not-for-profit sectors.

\section{References}

1. Hæger K. The Illustrated History of Surgery: Harold Starke Publishers; 2000.

2. Lister J. On the use of carbolic acid. The Lancet 1867;90:595.

3. Worboys M. Joseph Lister and the performance of antiseptic surgery. Notes Rec R Soc Lond 2013;67:199-209.

4. The Lancet. The Lancet 1873;101:903-15.

5. Jessney B. Joseph Lister (1827-1912): a pioneer of antiseptic surgery remembered a century after his death. J Med Biogr 2012;20:107-10.

6. History of LISTERINE@. Available from: https://www. listerine-me.com/about. Accessed 16 Apr 2020.

7. Carson EA, Toodayan N. Ignaz Philipp Semmelweis (1818-1865): herald of hygienic medicine. Med J Aust 2018;209:480-2.

8. Wyklicky H, Skopec M. Ignaz Philipp Semmelweis, the prophet of bacteriology. Infect Control 1983;4:367-70.

9. Ligon BL. Biography: Historical moments in the recognition of hand hygiene for control of infections: A short biography of Ignaz Philipp Semmelweis (1818-1865). Semin Pediatr Infect Dis 2001;12:154-9.

10. COVID-19: Compulsory to wear mask when leaving the house, says Lawrence Wong. Available from: https:// www.channelnewsasia.com/news/singapore/COVID19wearing-masks-compulsory-lawrence-wong-12640828. Accessed 16 Apr 2020.

11. Cowling BJ, Ali ST, Ng TW, et al. Impact assessment of non-pharmaceutical interventions against coronavirus disease 2019 and influenza in Hong Kong: an observational study. Lancet Public Health 2020;5:e279-88.

12. Leung NH, Chu DK, Shiu EY, et al. Respiratory virus shedding in exhaled breath and efficacy of face masks. Nat Med 2020;26:676-80. 